\title{
PD-1 blockade attenuates immunosuppressive myeloid cells due to inhibition of CD47/SIRPa axis in HPV negative head and neck squamous cell carcinoma
}

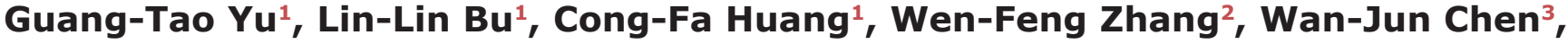 \\ J. Silvio Gutkind ${ }^{3}$, Ashok B. Kulkarni ${ }^{4}$, Zhi-Jun Sun ${ }^{1,2,4}$ \\ ${ }^{1}$ The State Key Laboratory Breeding Base of Basic Science of Stomatology \& Key Laboratory of Oral Biomedicine, Ministry of \\ Education, Wuhan University, Wuhan, China \\ ${ }^{2}$ Department of Oral Maxillofacial-Head Neck Oncology, School and Hospital of Stomatology, Wuhan University, Wuhan, China \\ ${ }^{3}$ Oral and Pharyngeal Cancer Branch, Laboratory of Cell and Developmental Biology, National Institute of Dental and \\ Craniofacial Research, National Institutes of Health, Bethesda, MD, USA \\ ${ }^{4}$ Functional Genomics Section, Laboratory of Cell and Developmental Biology, National Institute of Dental and Craniofacial \\ Research, National Institutes of Health, Bethesda, MD, USA \\ Correspondence to: \\ Zhi-Jun Sun, e-mail: sunzj@whu.edu.cn \\ Keywords: HNSCC, myeloid-derived suppressor cell, tumor associated macrophagy, PD-1 \\ Received: August 10, $2015 \quad$ Accepted: October 26, $2015 \quad$ Published: November 07, 2015
}

\section{ABSTRACT}

Myeloid-derived suppressor cells (MDSCs) and tumor associated macrophages (TAMs) play key roles in the tumor immune suppressive network and tumor progression. However, precise roles of programmed death-1 (PD-1) in immunological functions of MDSCs and TAMs in head and neck squamous cell carcinoma (HNSCC) have not been clearly elucidated. In the present study, we show that PD-1 and PD-L1 levels were significantly higher in human HNSCC specimen than in normal oral mucosa. MDSCs and TAMs were characterized in mice and human HNSCC specimen, correlated well with PD-1 and PD-L1 expression. aPD-1 treatment was well tolerated and significantly reduced tumor growth in the HNSCC mouse model along with significant reduction in MDSCs and TAMs in immune organs and tumors. Molecular analysis suggests a reduction in the CD47/SIRPa pathway by PD-1 blockade, which regulates MDSCs, TAMs, dendritic cell as well as effector $T$ cells. Hence, these data identify that PD-1/PD-L1 axis is significantly increased in human and mouse HNSCC. Adoptive aPD-1 immunotherapy may provide a novel therapeutic approach to modulate the micro- and macro- environment in HNSCC.

\section{INTRODUCTION}

Head and neck squamous cell carcinoma (HNSCC), with more than 450,000 newly diagnosed cases every year, is the $6^{\text {th }}$ most common cancer worldwide [1]. As the oral cavity is the most frequent site $(\sim 90 \%)$ affected in HNSCC, it impacts highly critical functions of respiration, swallowing food and water as well as speech [2]. In developing countries, the tobacco-related human papillomavirus (HPV)-negative $\mathrm{HNSCC}$ has more morbidity and mortality than HPV-positive HNSCC [3]. HPV-negative HNSCC is usually accompanied by mutations of $p 53$ and loss of expression of PTEN [3, 4]. Although in recent years significant advances have been made in targeted therapies, HNSCC recurrence, resistance to chemo-radiotherapy and cervical lymph node metastasis persist as the most important factors affecting the poor prognosis of patients, particularly in refractory HPV-negative HNSCC. Therefore identification and characterization of the molecular mechanisms underlying HNSCC initiation and progression are a priori for timely diagnosis and developing effective treatment.

Various mechanisms have been proposed for the resistance of HNSCC to immune recognition and response, including recruitment of myeloid derived suppressor cells (MDSCs), tumor associated macrophages (TAMs), regulatory T cells (Tregs), and local secretion of "alternatively activated" immunosuppressive soluble 
factors such as TGF $\beta 1$, IL10 and IL13 [5]. Recent advances in therapeutic antibodies, cancer vaccines, and adoptive T-cell therapy (ACT) have shown promising therapeutic potential of immunotherapy in treating patients with cancer [6]. Tumor-mediated immunosuppression is also considered to be a major barrier for successful cancer immunotherapy. Recent evidence has suggested that tumor-mediated immunosuppression by the up-regulation of coinhibitory immune checkpoints such as programmed death 1 (PD-1) and cytotoxic T-lymphocyte antigen 4 (CTLA-4) represent major obstacles to the generation and maintenance of clinically meaningful antitumor immunity $[7,8]$.

PD-L1 (a principal ligand of PD-1), known to be expressed by cells in the tumor microenvironment, engages $\mathrm{PD}-1$ on $\mathrm{T}$ cells and subsequently triggers inhibitory signaling, downstream of the T-cell receptor, blocking effector functions and reducing the T-cell killing capacity [9]. PD-L1 can be constitutively expressed on the surface of cancer cells through poorly characterized oncogenic signaling pathways $[10,11]$. PD-L1 is also expressed in immune cells in response to the presence of immune-stimulating cytokines [12]. The important role of PD-1/PD-L1 axis in the tumor immunosuppressive effect stems from recent clinical trials of PD-1 blockade that resulted in significant survival benefit with minimal toxicity to patients with advanced melanoma, renal cell carcinoma, and non-small cell lung cancer [13-16].

In the current study, we report that significant increase in PD-1/PD-L1 expression is an important immunosuppressive mechanism in human and mouse HNSCC. Oncogene activation by the conditional knockout of Pten and Tgfbrl may contribute to the over-expression of PD-L1 with concomitantly significant increase in MDSCs and TAMs. Moreover, we discovered that the blockade of PD-1 significantly reduces $\mathrm{CD}_{11} \mathrm{~b}^{+} \mathrm{Gr} 1^{+}$ and $\mathrm{CD} 11 \mathrm{~b}^{+} \mathrm{F} 4 / 80^{+}$cells in immune organs as well as in tumors of the mouse model. Our study, in direct relevance to clinical application, demonstrates that targeting PD-1/ PD-L1 can lead to durable antitumor immunity and curative outcome, with remarkable reduction in MDSCs and TAMs followed by enhanced immunoreactivity of $\mathrm{CD} 8^{+} \mathrm{T}$ and $\mathrm{CD} 4^{+} \mathrm{T}$ cells. These findings will be valuable in developing good strategies aimed at achieving more effective immunotherapy to treat HNSCC.

\section{RESULTS}

\section{Increased expression of PD-1/PD-L1 in human HNSCC}

To determine whether PD-1/PD-L1 expression was associated with HNSCC in humans, we searched the publicly available dataset of cancer using the Oncomine database [17]. In a meta-analysis of 18 datasets of head and neck cancers gene expression profiling, the increased CD274 (gene encoding PD-L1) and CD279 (gene encoding PD-1) DNA copy number, as well as increased mRNA expression of this genes, was significantly increased in HNSCC as compared with the controls $(P<0.05$, Fig. S1A-S1C). To evaluate PD-1/ PD-L1 levels in human HNSCC tissues, we performed immunohistochemistry in human HNSCC sections (Fig. 1A). PD-1 immunostaining revealed elevated levels in inflammatory cells of the cancerous tissue, and in particular in the invasive front of the tumor (Fig. 1A). PD-L1 immunostaining displayed its predominant expression in membrane and cytoplasm of HNSCC cells. There was significantly increased immunostaining for PD-1/PD-L1 in human HNSCC $(n=86)$ as compared with dysplasia $(n=12)$ and normal oral mucosa $(n=32)$ (Fig. 1B).

\section{Increased PD-1/PD-L1 expression in HNSCC tissue is independent of HPV status}

A recent interesting report identified the possible over-expression of PD-1/PD-L1 in human HNSCC, particularly in human papilloma virus (HPV) positive patients. However, in the present patient cohort the main anatomy origin of HNSCC was from oral cavity. Using p16 immunostaining and HPV DNA in situ hybridization technique to monitor HPV infection, we found that there was no statistically significant difference in PD-1/PD-L1 expression in HPV+ $(n=12)$ and HPV- $(n=74) \mathrm{HNSCC}$ (Fig. 1C and 1D). This result prompted us to explore whether there was a difference in PD-1 and PD-L1 expression in other viral-associated cancer settings. We searched for viral related cancer datasets including TCGA data using the Oncomine database. Our findings suggested that there are no significant differences in the CD279/ CD274 DNA copy number or the mRNA levels in HPVrelated HNSCC or HPV-related cervical cancer (Fig. S2 and S3). Additionally, there is no difference in either CD279 or CD274 expression in Epstein-Barr virus-related lymphoma or Hepatitis B virus/Hepatitis C virus-related hepatocellular carcinoma (Fig. S2 and S3). These results indicated that PD-1 over-expression potentially play an important role in both HPV+ and HPV- HNSCC.

\section{PD-1/PD-L1 protein levels correlate with MDSCs and TAMs in human HNSCC}

Recent studies have demonstrated that MDSCs and TAMs are predominantly cancer immune suppressor cells [5], which prompted our study on the correlation of PD-1/PD-L1 with MDSCs and TAMs. Immunostaining with specific antibodies for CD68 and CD163, were used to stain the M2 type macrophages in human HNSCC tissue array. As shown in Fig. 1A, an increase in CD68 and CD163 expression in the tumor areas of HNSCCs compared with normal mucosa were observed 
A

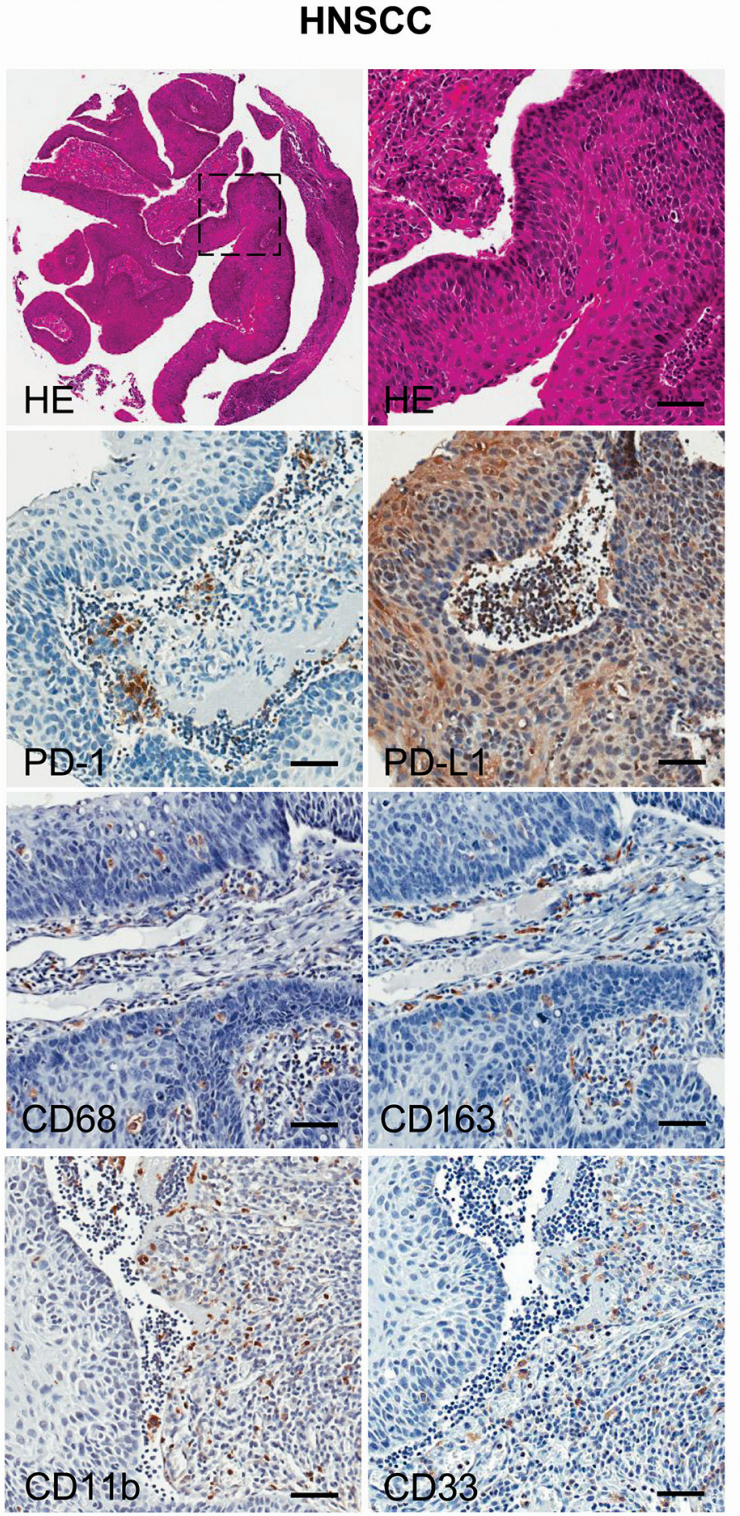

B
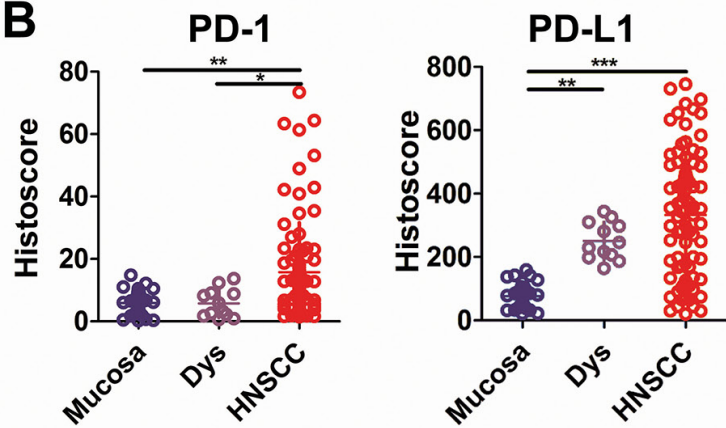

C

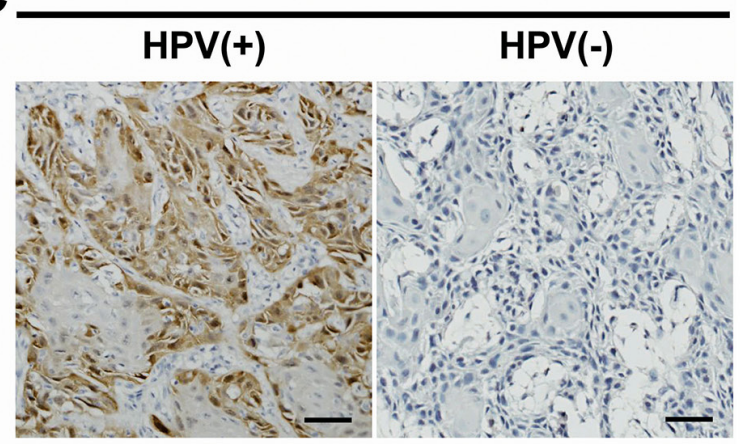

D

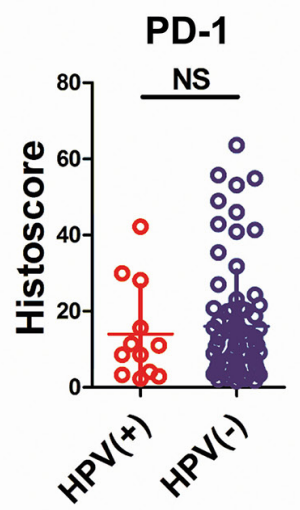

PD-L1
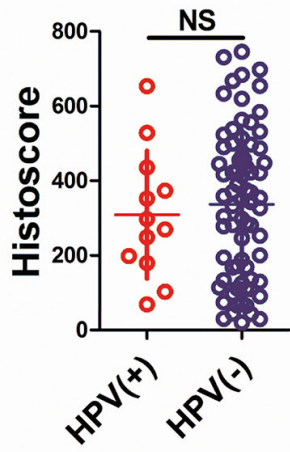

$\mathbf{E}$

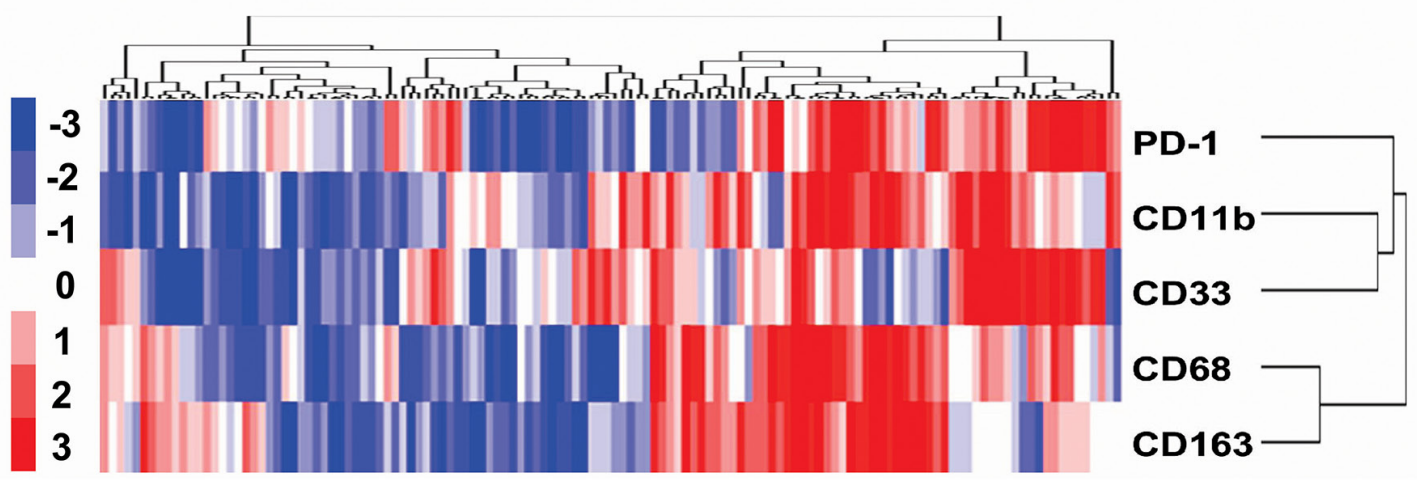

Figure 1: High expression of PD-1/PD-L1 in human head neck squamous cell carcinoma. A. representative Hematoxylineosin (HE) and immunohistochemistry staining of PD-1, PD-L1, CD68, CD163, CD11b and CD33 in HNSCC tissue. Scale bar, $50 \mu \mathrm{m}$. B. quantification of immunohistochemical histoscore of PD-1 and PD-L1 among oral mucosa $(n=32)$, dysplasia (Dys, $n=12)$ and head neck squamous cell carcinoma (HNSCC, $n=86$ ). (All data are presented as mean \pm SEM, One way ANOVA with post Tukey test. ** $P<0.01$; $\left.{ }^{* * *} P<0.001\right)$. C. representative immunohistochemistry staining of p16 to identify HPV $+(n=12)$ and HPV- $(n=74)$ HNSCC. Scale bar, $50 \mu \mathrm{m}$. D. PD-1 and PD-L1 histoscore of HPV+ and HPV- in HNSCC. NS, No significance. E. hierarchical clustering of PD-1, CD68, CD163, $\mathrm{CD} 11 \mathrm{~b}$ and CD33 immunohistochemical results in human HNSCC, statistic including mucosa, dysplasia and HNSCC $(n=130)$. 
(see quantification in Fig. S4A). Additionally, specific antibodies for $\mathrm{CD} 11 \mathrm{~b}$ and $\mathrm{CD} 33$ were used to stain the immune cells which are similar to mice $\mathrm{Gr}^{+} \mathrm{CD} 11 \mathrm{~b}^{+}$ MDSCs (see quantification in Fig. S4A). The expression of CD68, CD163, CD11b and CD33 was not related with the HPV+ status (Fig. S4B). By hierarchy clustering and linear regression, we found that the expression of PD-1 was closely related to the expression of CD11b, CD33, CD68 and CD163, and in particular closely to CD11b and CD33 (Fig. S4C and Fig. 1E). These observations suggest that PD-1/PD-L1 are closely related to the TAMs as well as MDSCs in human HNSCC. PD-1/PD-L1 expression and the TAMs or MDSCs population were increased in both HPV+ and HPV- HNSCC.

\section{The loss of tumor suppressor genes increases the expression of PD-L1 with TAMs and MDSCs in mice}

Our previous work reported a spontaneous development of HNSCC in a mouse model by combined deletion of important tumor suppressors Pten and Tgfbrl [18]. The tumor bearing mice showed significantly increased expression of $\mathrm{CD} 11 \mathrm{~b}+$ and $\mathrm{Gr} 1+$ cell populations in tumors and immune organs. To detect multiple cytokines and chemokines in the mouse HNSCC, we performed mouse cytokine antibody array which profiles the expression of 40 key cytokine genes involved in inflammation of mouse HNSCC tissues (Fig. 2A). Surprisingly, we found that most significantly increased cytokines such as sICAM-1 (CD54), M-CSF CXCL1, CXCL2, CCL2 in the Tgfbr1/Pten 2cKO HNSCC may attract monocytes. By quantitative PCR we found that indeed the expression of important cytokines Cd54, Csf-1, Cxcl1, Cxcl2 and Ccl2 was significantly increased in $2 \mathrm{cKO}$ mouse HNSCC tumor lysates as compared with $2 \mathrm{cKO}$ mouse tongue and the control tongue (Fig. S5: $n=5$ respectively). We also found a remarkable increase in $\mathrm{CD}_{11 b^{+}} \mathrm{Gr} 1^{+}$MDSCs (Fig. 2B: $n=6$ respectively, $P<0.001)$ as well as $\mathrm{CD} 11 \mathrm{~b}^{+} \mathrm{F} 4 / 80^{+}$ TAMs (Fig. 2B: $n=6$ respectively, $P<0.001$ ) in Tgfbrl/ Pten 2cKO HNSCC. We further confirmed increased expression of PD-1, PD-L1 with CCL2 and CXCL1 in the tumor lysaytes of $2 \mathrm{cKO}$ mice as compared with syngeneic counterparts (Fig. 2C). A recent report indicated that activation of oncogene Akt increases the expression of PD-L1. Thus, we explored the exact role of loss of function of Pten or Tgfbrl in PD-L1 expression. Western blot results consistently suggested that the loss of PTEN and/or TGFBR1 increased expression of PD-L1 in human head neck cell line CAL27 (Fig.2D) and FaDu (Fig. S6). This interesting finding has also been confirmed by the observation of increased PD-L1 expression in mouse HNSCC of Pten conditional knockout (Pten cKO) mice, $T g f b r l$ conditional knockout (Tgfbrl $\mathrm{cKO}$ ) mice and Pten/Tgfbrl 2cKO mice (Fig. 2E).

\section{Blockade of PD-1 prevents tumorigenesis in a HNSCC mouse model}

To determine the impact of PD-1 on carcinogenesis in vivo, we utilized Tgfbrl/Pten 2cKO mouse HNSCC model for chemopreventive tumorigenesis studies. The initial dosage of the inhibiting PD-1 antibody was applied at day 12. As the experimental paradigm shown in Fig. 3A, we found that PD-1 blockade produced a decrease in tumor growth, which indicated that in vivo inhibition of PD-1 using RMP1-14 antibody $(10 \mathrm{mg} / \mathrm{kg}$ intraperitoneally every other day) will delay (Fig. 3B) tumorigenesis in head and neck area as well as in tongue of the immunocompetent mice. The PD-1 blockade did not cause additional cytotoxicity as judged by gain of body weight in the treated mice as compared to the vehicle only group ( $n=6$ respectively, $P<0.001$, Fig. 3C). Additionally, the head and neck tumor growth curve and the number and size of the tumor demonstrated that PD-1 blockade effectively reduced the tumor burden and number of head neck tumors (Fig. 3D and 3E).

\section{Blockade of PD-1 decreases MDSCs and TAMs in HNSCC mouse model}

To determine whether PD-1/PD-L1 blockade decreases the MDSCs as well as TAMs, we performed flow cytometry analysis on the cells from the spleen, lymph node, and blood as well as tumor tissue of Tgfbr1/Pten $2 \mathrm{cKO}$ mice with or without $\alpha \mathrm{PD}-1$ treatment. We found that PD-1 blockade remarkably reduced $\mathrm{CD} 11 \mathrm{~b}^{+} \mathrm{Gr} 1^{+}$MDSCs in spleen, lymph node, blood as well as in tumor as compared with the vehicle only and wild-type syngeneic mice (Fig. 4A and Fig. S7A). The CD11b $\mathrm{Gr}^{+}{ }^{+}$MDSCs are even significantly attenuated in spleen and tumor. Western blot analysis showed a significant decrease in CXCL1 and iNOS levels in tumor lysates of $\alpha \mathrm{PD}-1$ blockade group as compared with vehicle only group (Fig. 4B). Immunofluorescence assay further showed a significant decrease in $\mathrm{Gr}^{+} \mathrm{CD} 11 \mathrm{~b}^{+}$ double positive MDSCs cell population as compared with control group (Fig. 4C and Fig. S7B). These results support our hypothesis that PD-1 blockade can effectively decrease MDSCs and TAMs in vivo.

In addition to MDSCs, we also investigated $\mathrm{CD} 11 \mathrm{~b}^{+} \mathrm{F} 4 / 80^{+}$TAMs in $\alpha \mathrm{PD}-1$-treated $2 \mathrm{cKO}$ mice as compared with vehicle only group. The flow cytometry analysis showed similar results to those seen in MDSCs. Tumor bearing mice had a significant increase in TAMs that were significantly attenuated by $\alpha \mathrm{PD}-1$ treatment particularly in spleen as well as in the tumors (Fig. 4D and Fig. S8).

\section{Inhibition of PD-1 reverses the immune suppression by promoting maturation of dendritic cells and increase in $\mathrm{CD8}^{+}$and $\mathrm{CD4}^{+} \mathrm{T}$ cell in vivo}

The balance between effector immune cells such as $\mathrm{CD} 8^{+}$cytotoxic $\mathrm{T}$ cells and $\mathrm{CD} 4^{+}$"helper" $\mathrm{T}$ cells) and 
A

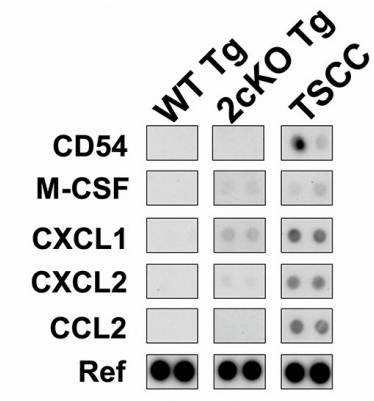

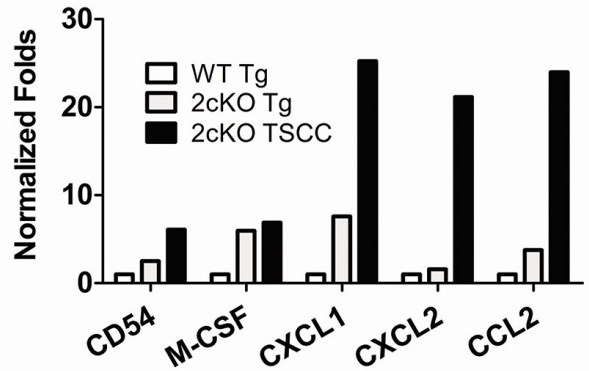

B

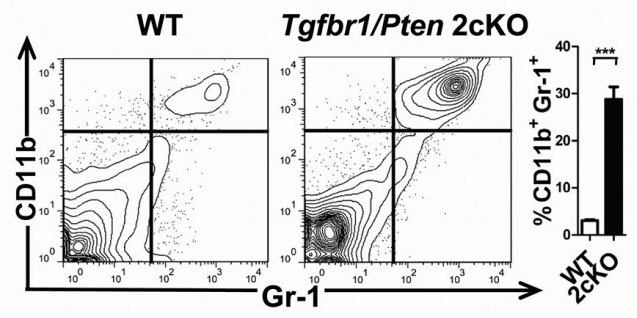

C
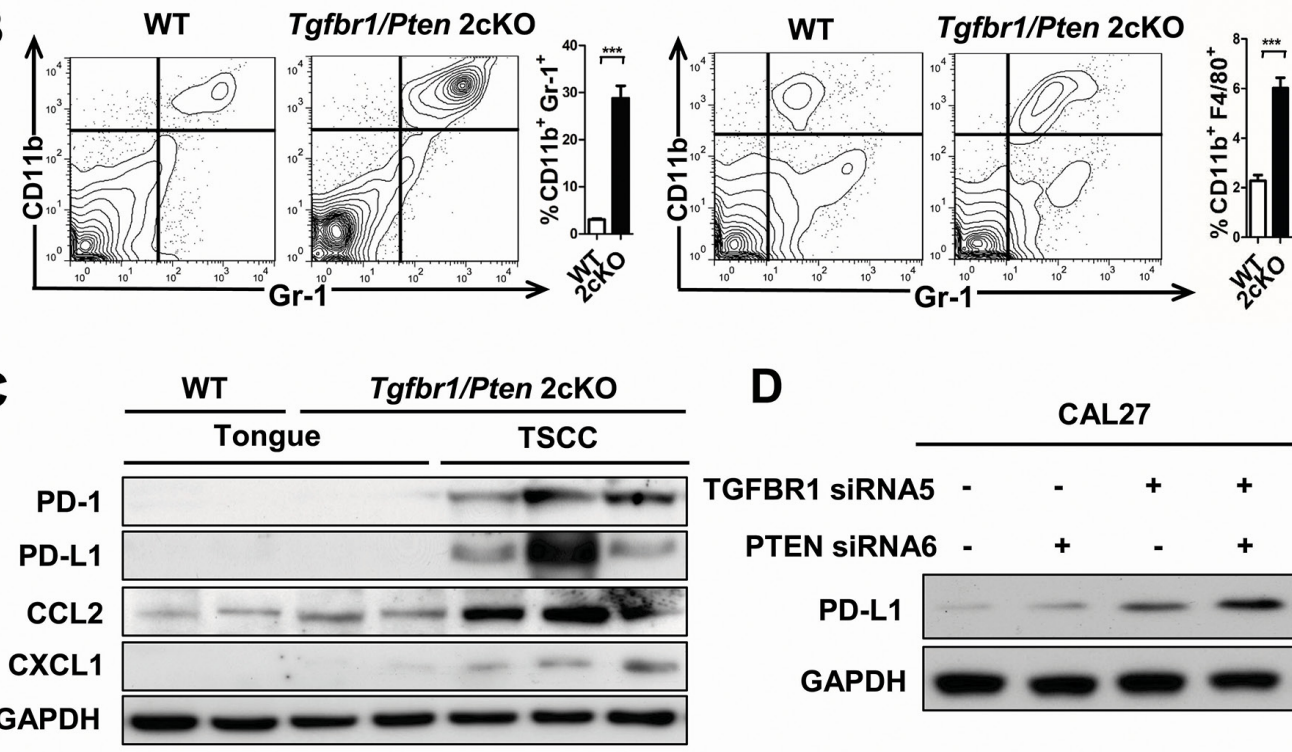

D

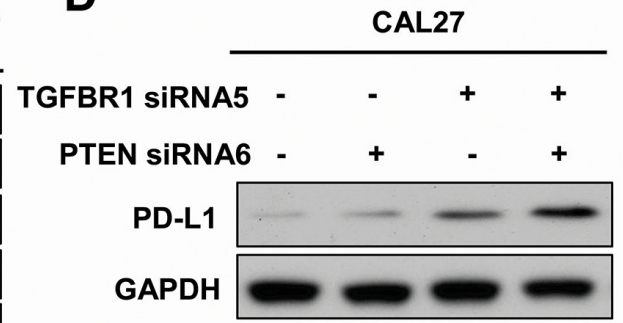

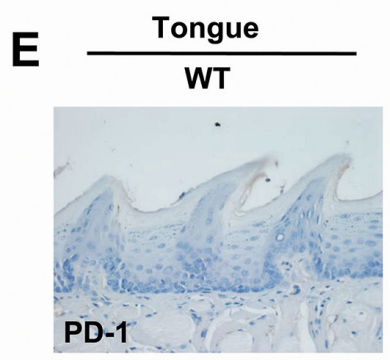

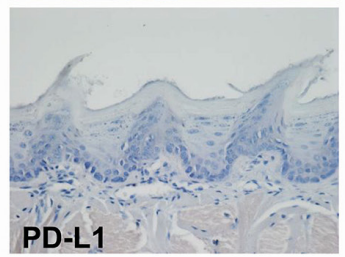

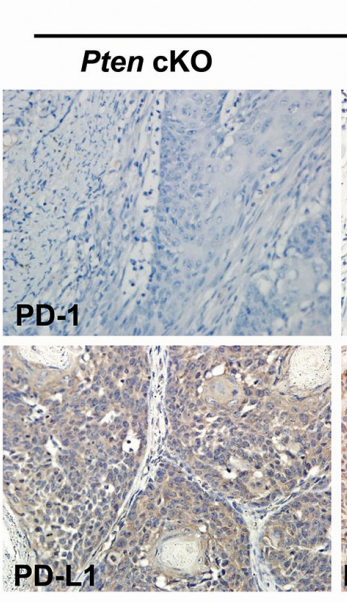

HNSCC

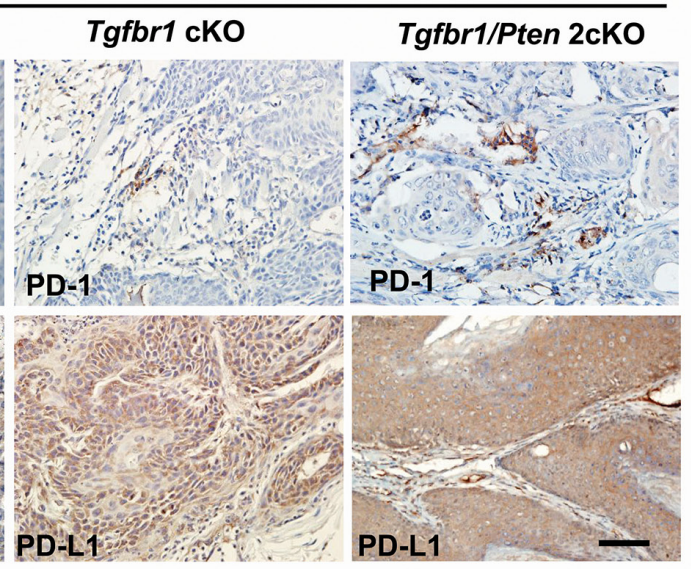

Figure 2: Combined deletion of Pten and Tgfbr1 increased expression of PD-1/PD-L1 induced immune suppression status in mice HNSCC. A. antibody array (left) shows increase of CD54, M-CSF, CXCL1, CXCL2 and CCL2 in Tgfbr1/Pten 2cKO mice tongue squamous cell carcinoma (TSCC) as compared with Tgfbrl/Pten $2 \mathrm{cKO}$ tongue (Tg) and wide type tongue (WT Tg, $n=5$ mice respectively). Quantitative of dot blotting by normalized with housekeep genes (Ref) using Image J (right). B. there was significant difference between the expression level of $\mathrm{CD} 11 \mathrm{~b}^{+} / \mathrm{Gr}^{+}$and $\mathrm{CD} 11 \mathrm{~b}^{+} / \mathrm{F} 4 / 80^{+}$cell population in the spleen of tumor bearing mice as compared with spleen of wide type mice. $(n=6$ mice respectively, $t$ test, $* * * P<0.001)$. C. western blot indicate increase of PD-1, PD-L1, CCL2 and CXCL1 in Tgfbrl/Pten 2cKO mice tongue squamous cell carcinoma (TSCC) as compared with Tgfbrl/Pten 2cKO tongue (Tg) and wide type tongue (WT Tg). GAPDH was used as the internal protein loading control. Experiment were repeated twice. D. siRNA knock down assay suggest loss function of Tgfbrl and Pten increase expression of PD-L1 in CAL27 HNSCC cell line. Experiment were repeated twice and performed in another cell line. E. immunohistochemical staining indicate increase PD-1 and PD-L1 expression in Tgfbrl conditional knock out (Tgfbrl cKO, $n=5)$ mice HNSCC, Pten conditional knock out (Pten $\mathrm{cKO}, n=5)$ mice HNSCC and Tgfbrl/Pten $2 \mathrm{cKO}(n=5)$ mice HNSCC, Data presented as mean \pm SEM, One way ANOVA with post Tukey test. Scale bars $=50 \mathrm{um}$. 


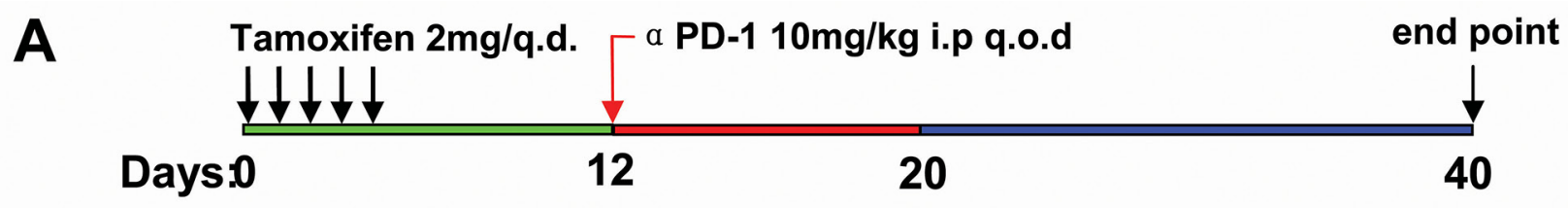

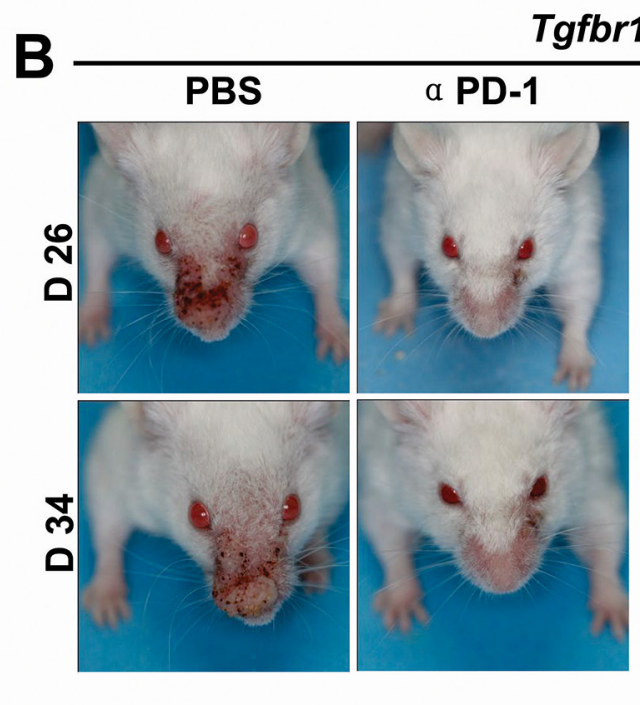

Tgfbr1/Pten 2cKO

B

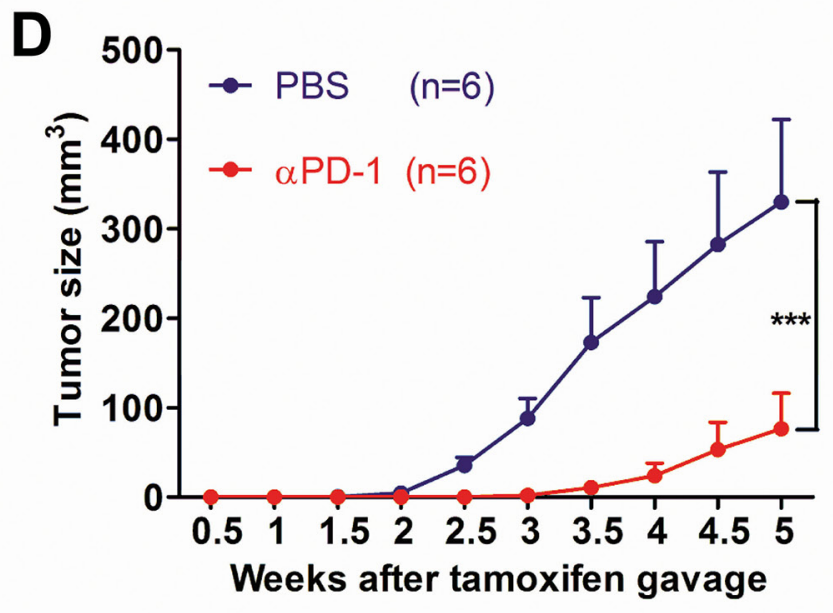

PBS

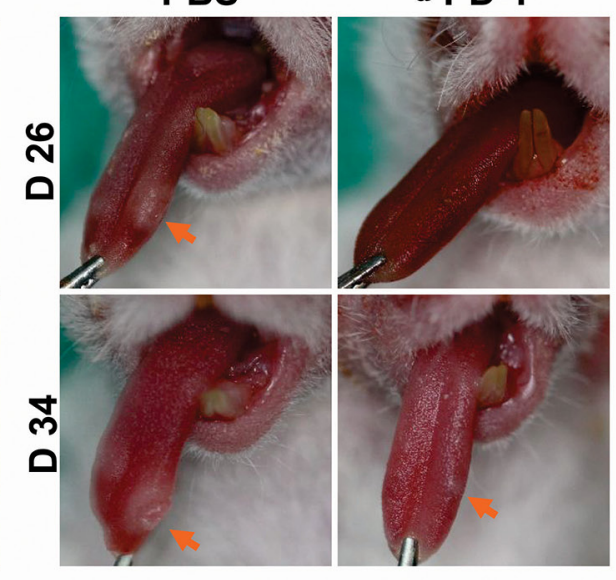

C Drug toxicity

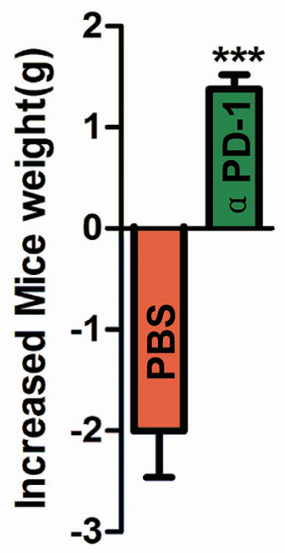

E

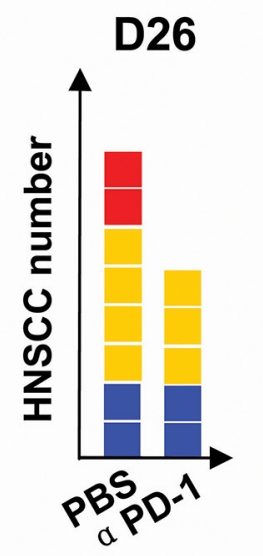

D34

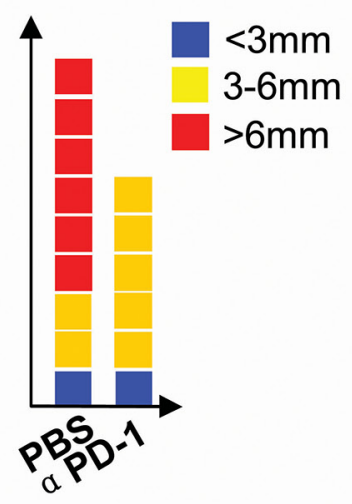

Figure 3: Inhibition of PD-1 by RMP1-14 prevents tumorigenesis and delays the onset of HNSCC in geneticallyengineered HNSCC mouse models. A. Tgfbrl/Pten 2cKO mice bearing carcinoma by tamoxifen were treated with $\alpha$ PD-1 intraperitoneally (i.p) every other day for 10 days or vehicle control treated ( $n=6$ mice respectively). B. representative photos of mice with external head and neck tumor (left panel) and tongue tumor (right panel) after treatment with $\alpha$ PD-1 or vehicle in day 26 and day 34 after tamoxifen gavage. C. drug toxicity was assessed by gained body weight of $T g f b r l / P t e n ~ 2 \mathrm{cKO}$ mice in each group. D. total tumor volume was assessed in $\alpha$ PD- 1 and control group twice a week after tamoxifen gavage. Data presented as mean \pm SEM (unpaired Student $t$ test, $* * * P<0.001)$. E. the number of tumor and the volume of each tumor were measured after treatment with $\alpha$ PD-1 or vehicle in day 26 and day 34 after tamoxifen gavage.

suppressor immune cells such as Tregs and MDSCs is a critical determinant of effective anti-tumor activity. We sought to determine the effect on dendritic cells (DCs) and $\mathrm{T}$ cells and found that PD-1 blockade significantly increased matured DCs population as well as increased $\mathrm{CD} 8^{+}$and $\mathrm{CD}^{+} \mathrm{T}$ cells. In tumor bearing Tgfbrl/Pten 2cKO mice, PD-1 blockade increased $\mathrm{MHC}-\mathrm{II}^{+}, \mathrm{CD} 40^{+}$, $\mathrm{CD}^{+} 6^{+}$cells in spleen (Fig. 5A and Fig. S9). In blood of tumor bearing Tgfbrl/Pten 2cKO mice, PD-1 blockade increased MHC-II ${ }^{+}$and $\mathrm{CD} 40^{+}$cells (Fig. 5B and Fig. S9). In tumor, inhibition of PD-1 effectively augmented $\mathrm{CD} 40^{+}, \mathrm{CD} 80^{+}, \mathrm{CD} 86^{+}$cells, and especially significantly increased MHC-II ${ }^{+}$DCs (Fig. 5C and Fig. S9). A recent report indicates that $\mathrm{CD} 47 / \mathrm{SIRP} \alpha$ axis plays an important role by reducing mature DCs and attracting tumor associate macrophages [19]. Our data suggested that CD47 and SIRP $\alpha$ significantly increased in tumor but this was attenuated by PD-1 blockade (Fig. 5D). 

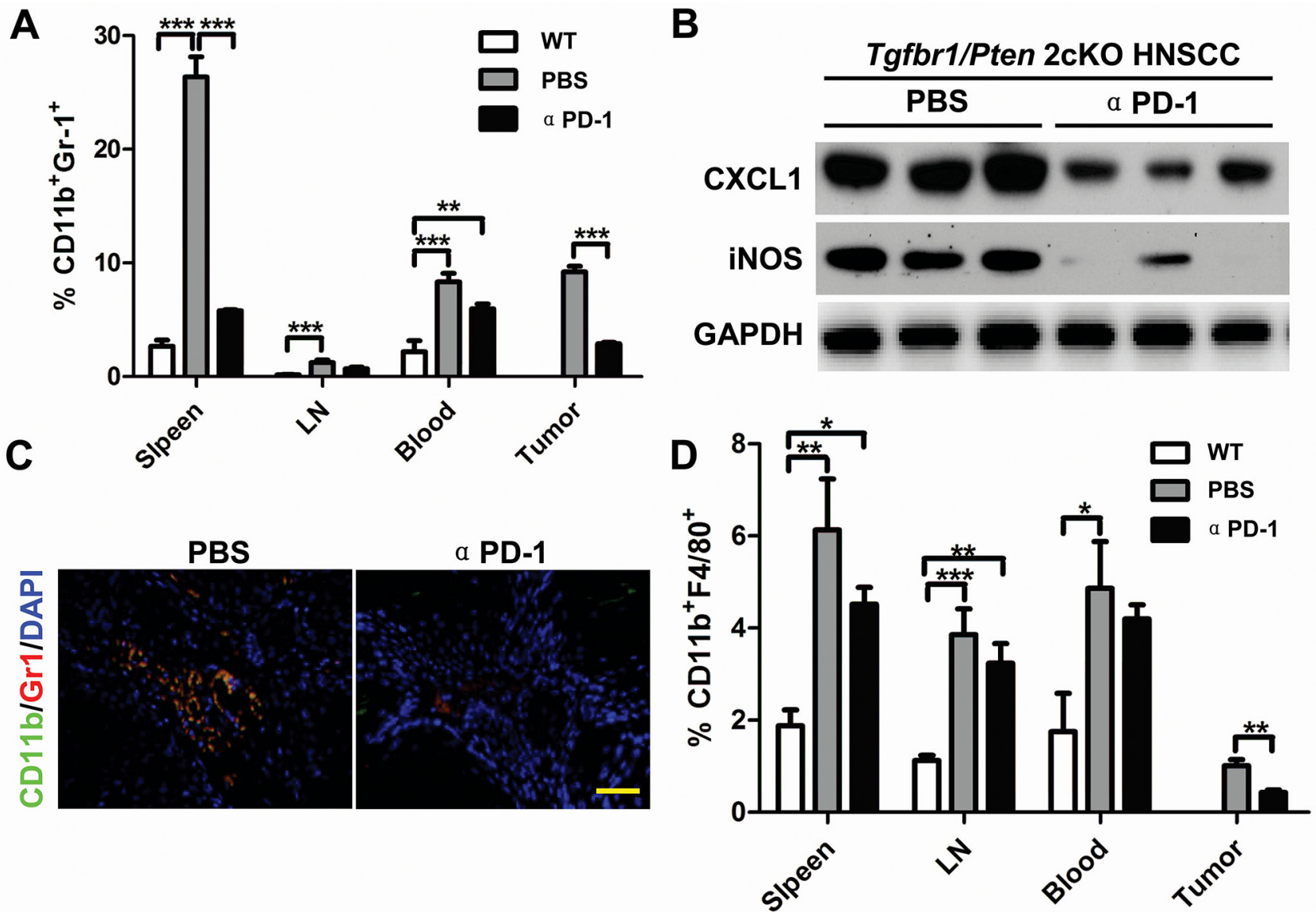

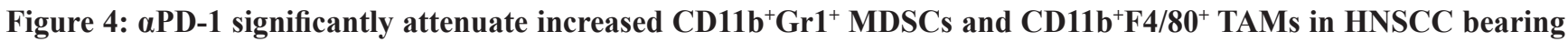
Tgfbr1/Pten 2cKO mouse model. A. quantification the percent of CD11 b $\mathrm{Gr}^{+}$MDSCs in spleen, lymph nodes, blood and tumor of mice bear tumor with or without $\alpha \mathrm{PD}-1$ treatment and wide type mice (Data presented as mean $\pm \mathrm{SEM}, n=6$ mice respectively, ANOVA with post Tukey test. $* * P<0.01 ; * * * P<0.001)$. B. western blot analysis revealed that the protein level of CXCL1 and iNOS were reduced in different degrees with PD-1 inhibition. GAPDH was used as a loading control. Data are representative of two independent experiments C. double immunofluorescence staining of $\mathrm{CD}_{11} \mathrm{~b}^{+} \mathrm{Gr}^{+}$cell population in mice HNSCC with or without $\alpha \mathrm{PD}-1$ treatment. Scale bar, $50 \mathrm{um}$. D. quantification of $\mathrm{CD} 11 \mathrm{~b}^{+} \mathrm{F} 4 / 80^{+}$tumor associated macrophage (TAMs) in spleen, lymph nodes, blood and tumor of mice bear tumor with or without $\alpha \mathrm{PD}-1$ treatment and wide type mice (Data presented as mean $\pm \mathrm{SEM}, n=6$ mice respectively, ANOVA with post Tukey test. $* P>0.05 ; * * P<0.01 ; * * * P<0.001)$.

The immunofluorescence analysis also indicated that CD47 was over expressed in both cancer cells and inflammatory cells. SIRP $\alpha$ was mainly expressed in inflammatory cells and overlapped with $\mathrm{CD} 47^{+}$cell in peritumor inflammatory cells. PD-1 blockade decreased the expression of CD47 and SIRP $\alpha$ (Fig. 5E).

To further investigate the number of $\mathrm{CD} 4^{+}$and $\mathrm{CD} 8^{+}$ $\mathrm{T}$ cells, we took advantage of flow cytometry and found inhibition of PD-1 significantly decreased PD- $1^{+}$cells in spleen, lymph node as well as in blood (Fig. 6A and 6B), accompanied by an increase in $\mathrm{CD}^{+}$(Fig. 6A and 6C) and $\mathrm{CD}^{+}$(Fig. 6A and 6D) $\mathrm{T}$ cells in spleen, lymph node and blood. In tumors, PD-1 blockade significantly decreased $\mathrm{PD}-1^{+}$cells accompanied by an increase in $\mathrm{CD}^{+}$and $\mathrm{CD}^{+} \mathrm{T}$ cells (Fig. $6 \mathrm{~A}$ and $6 \mathrm{E}$ ). Then, we investigated the expression of PD-1 and PD-L1 in mouse tumors with or without $\alpha$ PD-1 treatment (Fig. 6F). The reversal of immune tolerance status by PD-1 blockade can also be indicated by observation of reduced spleen size in $\alpha \mathrm{PD}-1$ group as compared with vehicle only group (Fig. 6G). Overall, these results suggest that the prior to the treatment peripheral effector/suppressor balance in PD-1 blocker treated mice is already skewed towards immunosuppression.

\section{DISCUSSION}

Suppression of the host immune system plays a major role in cancer progression. The activation of the co-inhibitory checkpoint molecule PD-1 in $\mathrm{T}$ cells and expansion of MDSCs are considered the major mechanisms for tumor to escape from immune surveillance [20]. Although targeted PD-1/PD-L1 therapy achieved a significant cure in melanoma and lung cancer $[21,22]$, the importance of this axis in HNSCC is less 

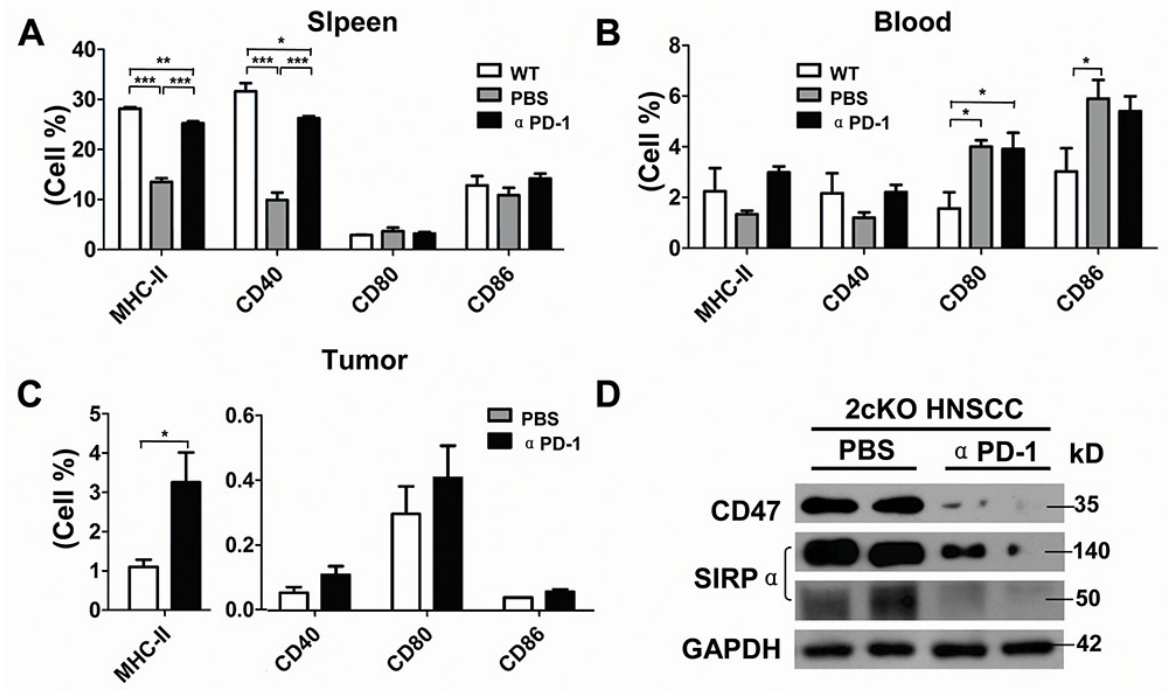

D

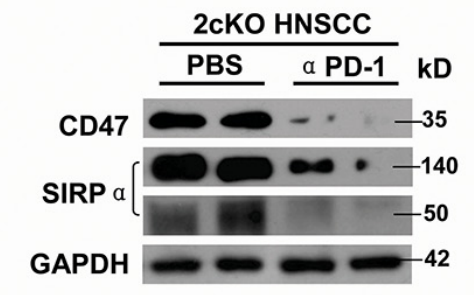

$\mathbf{E}$
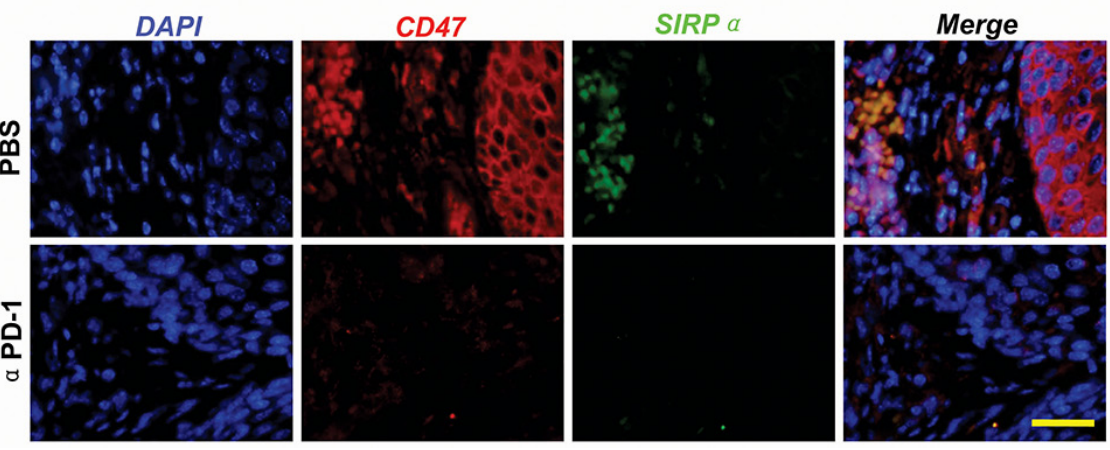

Figure 5: Inhibition of PD-1 significantly promotes maturation of DCs in HNSCC bearing Tgfbr1/Pten 2cKO mouse model. Percentage of MHC-II, CD40, CD80 and CD86 positive cells was determined by flow cytometry in spleen A. and lymph node B. from mice tumor with or without $\alpha \mathrm{PD}-1$ treatment and wide type mice (Data presented as mean \pm SEM, One way ANOVA with post Tukey test, $n=6$ mice respectively, $\left.{ }^{*} P<0.05 ; * * P<0.01 ; * * * P<0.001\right)$. C. percentage of MHC-II, CD40, CD80 and CD86 positive cells was determined by flow cytometry in twice bearing tumor with or without $\alpha$ PD-1 treatment $(t$ test, $* P<0.05)$. D. western blot analysis of CD47 and SIRP $\alpha$ levels in mice bearing tumor with or without $\alpha$ PD-1. Data are representative of two independent experiments. E. representative immunofluorescence images of CD47 and SIRP $\alpha$ in mice bearing tumor with or without $\alpha$ PD- 1 treatment are shown. Scale bar, 50 um.

recognized. For the first time, we demonstrate here that the increase of PD-1/PD-L1 axis correlates with expansion of key suppressor immune cell populations, MDSCs and TAMs, in human HNSCC as well as in HNSCC mouse model that develops spontaneous tumors. Moreover, our study provides direct evidence that systematic application of $\alpha$ PD-1 monoclonal antibody demonstrates a remarkable decrease in tumorigenesis with significantly reduced MDSCs and TAMs populations and increased effector $\mathrm{T}$ cells. Molecular analysis identified that $\alpha \mathrm{PD}-1$ treatment significantly decreases myeloid cells and chemokine levels as well as decrease in CD47/SIRP $\alpha$ signaling.

Alcohol/tobacco abuse and HPV infection are the main risk factors associated with the development of HNSCC $[23,24]$. Although HPV- HNSCCs are different from HPV+ HNSCC in several ways [25, 26], there is no significant difference in PD-1/PD-L1 expression between HPV+ and HPV- HNSCC [27, 28]. Our data further demonstrate that MDSCs and TAMs frequency is independent of HPV infection status. As compared with HPV+ tumors, PTEN loss was found to be more frequent in HPV- HNSCC [25]. We found PTEN loss promotes the expression of PD-L1 in HNSCC cell line and in the conditional $\mathrm{Pten}^{-/-}$mice, which is consistent with recent observations in breast and prostate cancers [29]. The present study also suggests that TGFBRl loss further enhances the expression of PD-L1 in HNSCC cell lines and conditional $\mathrm{Tg} f \mathrm{br} \mathrm{I}^{-/-}$mice, which indicate that loss of TGFBR1 may be an crucial molecular event leading to the accumulation of PD-L1 in both HPV infection and alcohol or tobacco use [18, 30]. Moreover, PTEN loss and TGFBR1 loss synergistically promote activation of PD-L1, likely by the activation of oncogenic Akt pathway in Tgfbr1/Pten 2cKO mice [31]. Taken together, our in vitro and in vivo studies revealed that loss of PTEN and TGFBR1 together promote the activation of PD-1 and PDL1 pathway in HNSCC, independent of the HPV infection status. 
A

- isotype $-\mathrm{WT}-\mathrm{PBS}-\mathrm{a} \mathrm{PD}-1$

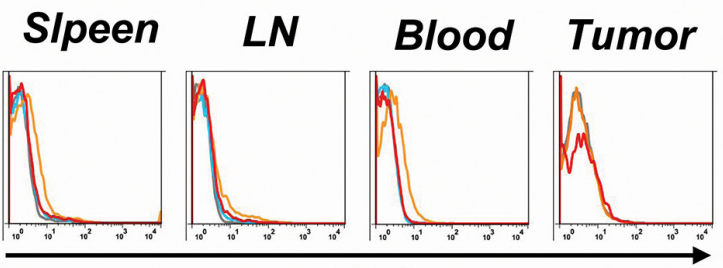

PD-1
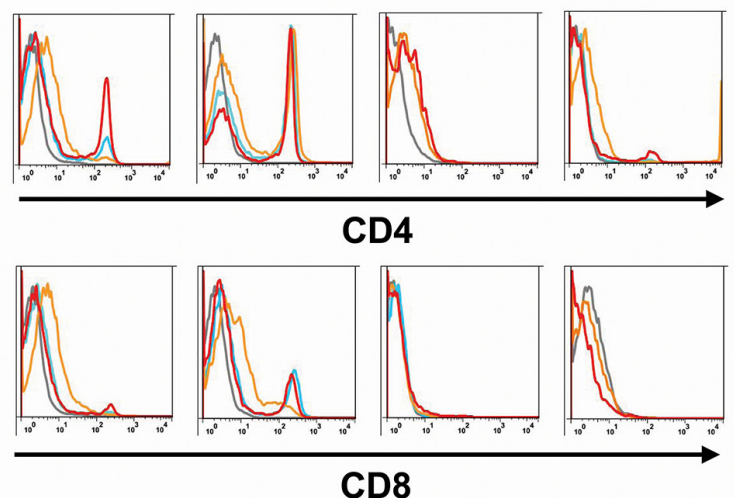

D

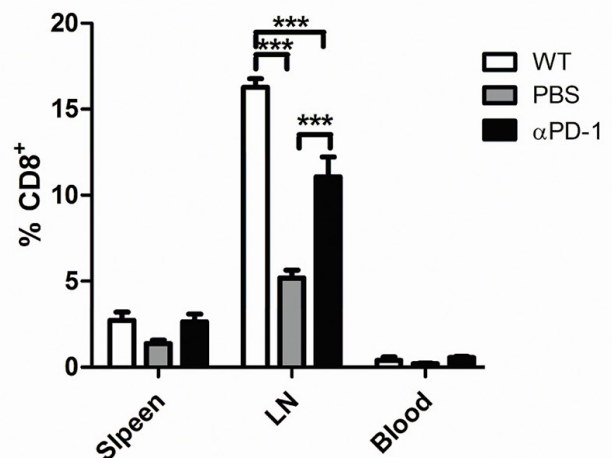

$\mathbf{F}$

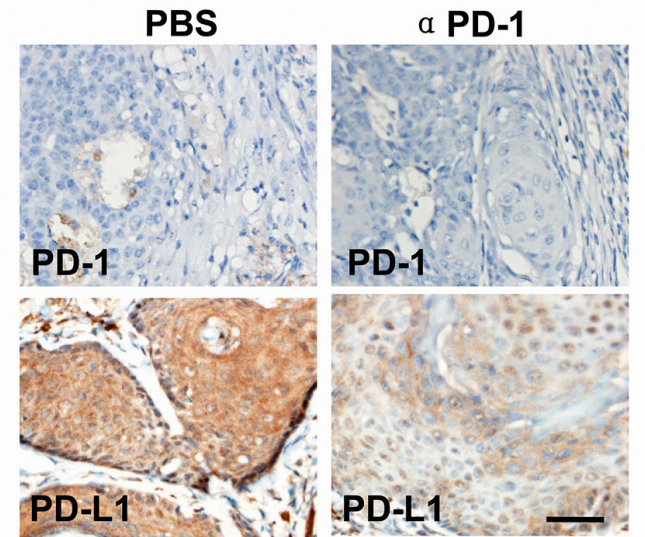

B

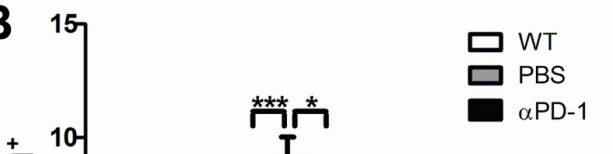

$T$

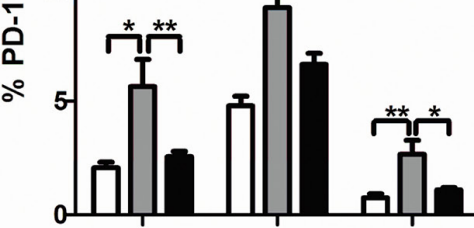

C

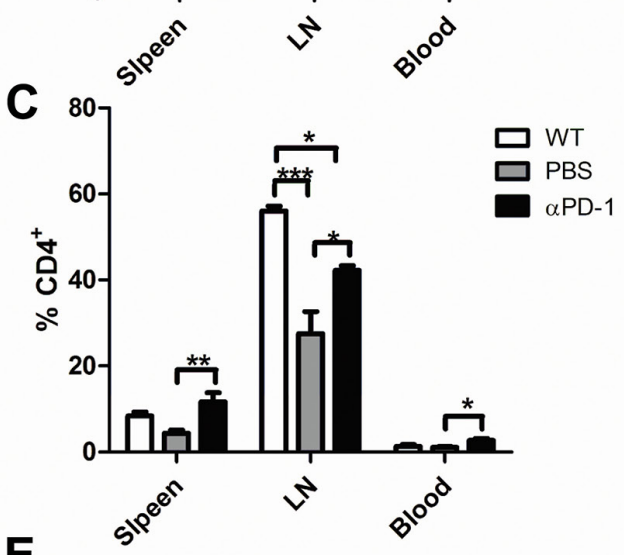

E

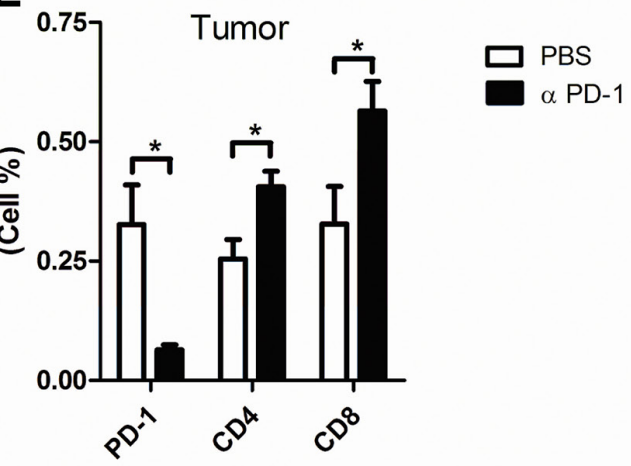

G

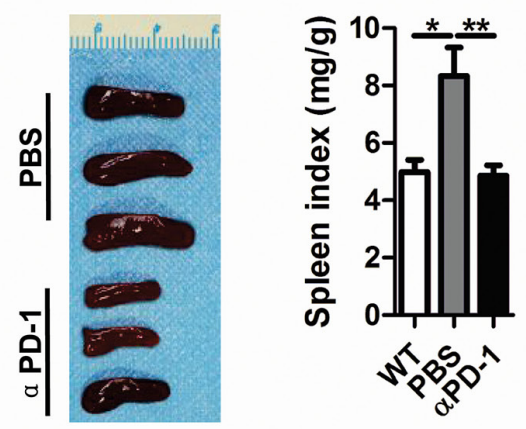

Figure 6: PD-1 blockade significantly increase $\mathrm{CD4}^{+}$and $\mathrm{CD8}^{+} \mathrm{T}$ cell in HNSCC mouse model. A. representative flow cytometry showed decrease staining population of PD- $1^{+}$and increase of $\mathrm{CD}^{+}$and $\mathrm{CD}^{+} \mathrm{T}$ cell in $\alpha \mathrm{PD}-1$ treatment group. Quantitative of

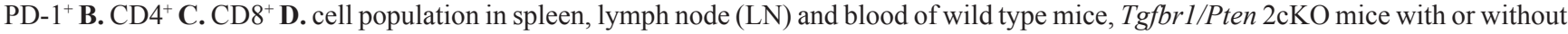
$\alpha$ PD-1 treatment $\left(n=6\right.$ mice respectively, One way ANOVA with post Tukey test. $\left.{ }^{*} P<0.05 ; * * P<0.01 ; * * * P<0.001\right)$. E. quantitative of $\mathrm{PD}-1^{+}, \mathrm{CD} 4^{+}$and $\mathrm{CD} 8^{+}$cell population in mice bearing tumor with or without $\alpha \mathrm{PD}-1$ treatment $\left(t\right.$ test, $\left.{ }^{*} P<0.05\right)$. F. representative images demonstrates the immunohistochemical analysis of PD-1 and PD-L1 in mice bearing tumor with or without $\alpha$ PD-1 treatment. Scale bar, 50um. G. representative gross photo (left) showed the size of spleen different between $\alpha \mathrm{PD}-1$ treatment group and vehicle group. Spleen index shows $\alpha \mathrm{PD}-1$ significantly inhibit compensatory growth in Tgfbrl/Pten $2 \mathrm{cKO}$ mice. (Data presented as mean $\pm \mathrm{SEM}, n=6$ mice respectively, right panel, One way ANOVA with post Tukey test. $* P<0.05 ; * *<0.01)$. 
More recent reports have suggested the close relationship of PD-1/PD-L1 with MDSCs and TAMs [32]. Our previous [18] and present study together reveals a significant accumulation of MDSCs and TAMs along with increase in putative myeloid cytokines and chemokines in HNSCC tumorigenesis in mice. We further confirmed that increased expression of PD-1, PD-L1 in HNSCC correlated with accumulation of MDSCs and TAMs in human and mouse HNSCC. As expected, PD-1 blockade significantly reduced tumorigenesis in Tgfbrl/Pten $2 \mathrm{cKO}$ mice. Moreover, a remarkable reduction of MDSCs cell populations in tumor and immune organs by PD-1 blockade was observed, which can be attributed to the decrease of CXCL1. The expression of iNOS in MDSC has been shown to be critical for the suppression of T cell [33]. Therefore, the reduction in iNOS further promotes the activation of T cell in tumor microenvironment. PD-1 has also been implicated in the regulation of $\mathrm{M} 2$ macrophages and inhibition of PD-1 can induce the polarization of macrophages to M1 phenotype [34]. The current study first outlines that PD-1 blockade has an antitumor function in HNSCC, at least partially, dependent on the role of CD47/ SIRP $\alpha$ which functions as a "do not eat me" signal in many malignancies. Blockade of CD47/SIRP $\alpha$ axis led to efficient and rapid phagocytosis of multiple tumor cell types [35]. In our in vivo study, down-regulation of expression of CD47 in tumor cells by blockade PD-1 may improve phagocytosis of macrophage to enhance antitumor immunity.

Analogous to macrophages, the current study also demonstrated $\alpha \mathrm{PD}-1$ treatment promotes maturation of DCs. With exposure to antigens stimuli, DCs undergo a maturation process by increasing expression of co-stimulatory molecules such as MHC-II, CD40, CD80 and $\mathrm{CD} 86$, producing pro-inflammatory cytokines and presenting antigens to T cells [36]. Indeed, blockade of PD-1 increased the expression levels of co-stimulatory molecular in mouse tumor and immune organ suggesting the condition of immune suppression was improved in the tumor microenvironment, which may be caused by decreased CD47/SIRP $\alpha$ signaling. Consistently, recent reports indicated that activation of the CD47/SIRP $\alpha$ signaling pathway enables to restrain DCs maturation [19] and that inhibition of CD47/SIRP $\alpha$ may increase DCsmediated antigen presentation [37]. The results in our study, especially in spleen and blood, demonstrated that the mechanisms by which tumor escape immune survelience depend on the tumor itself but also in changing conditions in tumor macro-environment [38].

PD-1/PD-L1 plays an important role in inhibiting tumor immune response by promoting $\mathrm{CD}^{+}$and $\mathrm{CD} 8^{+}$ $\mathrm{T}$ cells apoptosis [39]. In addition to directly reducing $\mathrm{CD}^{+}$and $\mathrm{CD} 8^{+} \mathrm{T}$ cells apoptosis, $\mathrm{PD}-1$ blockade may also restore $\mathrm{T}$ cell activity by decreasing the CD47 expression in the tumor microenvironment [40]. At the same time, DCs that could be partially activated by co-stimulatory molecules in the tumor microenvironment could then promote effective antitumor $\mathrm{T}$ cells responses [41]. The current study also revealed that blockade of PD-1 could decrease arginase 1 and iNOS which enhance T cells proliferation to promote antitumor immunity $[42,43]$. We have also demonstrated a significant correlation between PD-1 expression and infiltration of $\mathrm{CD} 11 \mathrm{~b}^{+} / \mathrm{CD} 33^{+}$ (markers of human MDSCs) cells in human HNSCC tissues microarray.

The clinical significance of PD-1 blockade for HNSCC treatment is supported by phase III single agent clinical trial of PD-1 antibody Nivolumab (BMS936558, NCT02105636; see review of Zandberg DP) [44]. Anti-PD-1 mAB appears to be generally less toxic as compared to anti-CTLA4 $\mathrm{mAB}$, with a slightly different toxicity profile such as pneumonitis [45]. To date, there are not too many general adverse events reported for anti-PD-1, including fatigue, pyrexia, chills and infusion reaction [46]. The current study suggests that targeting the PD-1/PD-L1 signaling pathway to reverse the immunosuppressive status has important therapeutic implications for the treatment of HNSCC. Nevertheless, we cannot completely exclude the possibility that PD-1 blockade may have indirect role on tumorigenesis through angiogenesis and by targeting cancer stem cell mediated by MDSCs and TAMs [47]. In addition, a recent report indicated increased MDSCs [16] and PD- $1^{+}$CD4 $\mathrm{T}$ cells [48] in cancer patients receiving chemo-radiotherapy, which provides a rationale for combined treatment with chemo-radiotherapy and PD-1 blockade.

In summary, we discovered a significant increase of PD-1/PD-L1 in HNSCC, which is tightly correlated with important immune suppressor cells, MDSCs and TAMs. Taking advantage of immunocompetent transgenic mouse HNSCC models, we observed a decrease in MDSCs, TAMs, and mature DCs as well as an increase in CD8 ${ }^{+}$ $\mathrm{T}$ cells and $\mathrm{CD} 4^{+} \mathrm{T}$ cells by PD- 1 blockade in micro- and macro- tumor environment. Therefore, we believe that therapeutically blocking the PD-1/PD-L1 pathway may prove to be a promising antitumor therapy for HNSCC.

\section{MATERIALS AND METHODS}

Detailed methods and procedures are provided in the Supplementary Data.

\section{Genetically modified mice}

All experiments were conducted in accordance with the guidelines of the Institutional Animal Care and Use Committee of the Wuhan University. Time inducible tissue-specific Tgfbrl/Pten 2cKO mouse (K14-Cre $e^{\mathrm{ERtam}+/}$; $T g f b r l^{\text {flox fllox }} ;$ Pten $\left.^{\text {flox fllox }}\right)$ were maintained and genotyped according to published protocols $[49,50]$. The details of $\mathrm{Tg} f b r \mathrm{cKO}$ HNSCC mouse (K14-Cre $\left.e^{\mathrm{ERtam+}+} ; \mathrm{Tg} f b r 1^{\text {flox/flox }}\right)$, 


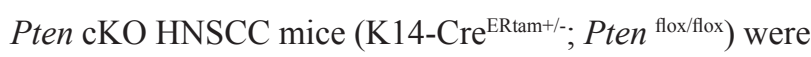
previously described $[49,50]$. All the mice were bred in the FVBN/CD1/129/C57 mixed background.

\section{PD-1 antibody treatment}

The in vivo MAb anti mPD1 antibody (RMP1-14) was purchased from BioXcell (West Lebanon, NH, USA) After oral gavage of tamoxifen for 5 consequent days, the Tgfbr1/Pten $2 \mathrm{cKO}$ mice were randomly divides into control group (PBS, i.p. daily, $n=6 \mathrm{mice}$ ), $10 \mathrm{mg} / \mathrm{kg}$ RMP1-14 treated group (i.p. daily: $n=6$ mice). RMP1-14 and vehicle treatment were performed 10 days after tamoxifen induction and the mice were observed for 18 days. Syngeneic wide type control mice $\left(\mathrm{K} 14-C r e^{\mathrm{ERtam}+/} ; \mathrm{Tg} f b r 1^{\text {flox/flox }} ; \mathrm{Pten}^{\text {flox/flox }}\right)$ treated with the same dose of tamoxifen were used as controls $(n=6)$. The tumor sizes were measured using a micrometer caliper and by taking photographs every other day. The mice were euthanized at the end of the studies (day 40 based on pilot study).

\section{Proteome profiler antibody array analysis}

The mouse cytokine array panel an array kit (ARY006, R\&D Systems) were used to analyze tissue lysates from pooled wide type tongue mucosa samples, Tgfbr1/Pten 2cKO tongue mucosa and 5 Tgfbr $1 /$ Pten $2 \mathrm{cKO}$ tongue SCC ( $n=5$ respectively) Average optical intensity of duplicate spots for each cytokine was normalized to the average of positive controls on the same chip using the Image J software (NIH, Bethesda, MD, USA).

\section{Flow cytometry analysis}

To obtain single cell suspensions, tumor tissues of Tgfbr1/Pten $2 \mathrm{cKO}$ mice with or without PD-1 blockade antibody RMP1-14 treatment were processed using a gentle Macs dissociator and a murine tumor dissociation kit (Miltenyi Biotec). Single cell suspensions from spleens, lymph node, and blood were prepared according to a standardized protocol [51]. Wild type controls with the same dose of tamoxifen were used for flow cytometry analysis.

\section{Cell culture and RNAi}

HNSCC cell lines CAL27 and FaDu were purchased from the American Type Culture Collection (ATCC, Manassas, VA) and genotype confirmed using STR methods. For the in vitro knockdown experiment, 2 TGFBR1 siRNA (siRNA5 and SiRNA6), 2 PTEN siRNA (siRNA5 and siRNA6) were used with negative control (Qiagen), and positive Cell Death siRNA (Qiagen). Validation of knock down efficiency using qPCR and Western blotting were performed as previously described $[49,50]$.

\section{Western blotting and quantitative real-time RT-PCR analysis}

Western blotting and quantitative real-time RT-PCR analysis were performed as previously described [49].

\section{Human HNSCC tissue array}

School and Hospital of Stomatology of Wuhan University Medical Ethics Committee approved this study, and informed consent was obtained from the patients before they underwent surgery. Custom made tissue microarray including $86 \mathrm{HNSCC}, 12$ oral epithelial dysplasia and 32 normal oral mucosa tissue samples were used for immunohistochemistry staining as previous described [4].

\section{Immunohistochemistry and immunofluorescence}

Tumors from $\mathrm{Tg} f \mathrm{fr} 1 /$ Pten $2 \mathrm{cKO}$ mice were dissected and fixed as previously described [31], and slides were stained with the appropriate antibody using a standard immunohistochemical and double immunofluorescence staining protocol as previously described [52].

\section{Scoring system, hierarchical clustering and data visualization}

Whole slices were scanned and quantified of histoscore using an Aperio ScanScope CS scanner with a background substrate for each slice, quantification as previously described [53]. The hierarchical analysis was achieved using the Cluster 3.0 with average linkage based on Pearson's correlation coefficient [54].

\section{Statistical analysis}

Statistical evaluations were undertaken with Graph Pad Prism version 5.0. One-way ANOVA followed by the post-Tukey multiple comparison tests were used to analyze the differences in protein levels, RNA levels and positive cells among each group. Student $t$ test was used to analyze immunostaining of the difference between the PD-1 blockade group and vehicle group. Two-tailed Pearson's statistics was used for the correlated histoscore. The mean values \pm SEM with a difference of $P<0.05$ were considered statistically significant.

\section{ACKNOWLEDGMENTS}

We apologize to colleagues whose primary research papers may not have been cited due to space constraints.

\section{CONFLICTS OF INTEREST}

No, there is no conflict of interest that I should disclose, having read the above statement. 


\section{GRANT SUPPORT}

This research was supported by National Natural Science Foundation of China 81272963, 81472528 (Z.J S.), 81272964,81472529 (W.F.Z), 81402241 (C.F.H.), and the Divison of Intramural Research, NIDCR, NIH, USA (A.B.K, W.J.C., and J.S.G). Z.J.S. was supported by program for new century excellent talents in university (NCET-13-0439), Ministry of Education of China.

\section{Authors' contribution}

Conception and design: G.-T. Yu, W.-J. Chen, J. S. Gutkind, A. B. Kulkarni, Z.-J. Sun Development of methodology: G.-T. Yu, L.-L. Bu, C.-F. Huang, A. B. Kulkarni, Z.-J. Sun Acquisition of data (provided animals, acquired and managed patients, provided facilities, etc.): G.-T. Yu, L.-L. Bu, C.-F. Huang, W.-F. Zhang, A. B. Kulkarni, Z.-J. Sun Analysis and interpretation of data (e.g., statistical analysis, biostatistics, computational analysis): G.-T. Yu, L.-L. Bu, C.-F. Huang, Z.-J. Sun Administrative, technical, or material support (i.e., reporting or organizing data, constructing database): G.T. Yu, L.-L. Bu, C.-F. Huang, A. B. Kulkarni, Z.-J. Sun Writing, review and/or revision of the manuscript: G.-T. Yu, W.-J. Chen, J. S. Gutkind, A. B. Kulkarni, Z.-J. Sun Study supervision: A. B. Kulkarni, Z.-J. Sun

\section{REFERENCES}

1. Jemal A, Bray F, Center MM, Ferlay J, Ward E, Forman D. Global cancer statistics. CA Cancer J Clin. 2011; 61:69-90.

2. Serafini P, Weed DT. The immune system in head and neck squamous cell carcinoma:Interactions and therapeutic opportunityies. Advances in Tumor Immunology and Immunotherapy. 2014:275-310.

3. Warnakulasuriya S. Global epidemiology of oral and oropharyngeal cancer. Oral Oncol. 2009; 45:309-316.

4. Zhi X, Lamperska K, Golusinski P, Schork NJ, Luczewski L, Kolenda T, Golusinski W, Masternak MM. Gene expression analysis of head and neck squamous cell carcinoma survival and recurrence. Oncotarget. 2015; 6:547-555.

5. Zou W. Immunosuppressive networks in the tumour environment and their therapeutic relevance. Nat Rev Cancer. 2005; 5:263-274.

6. Mellman I, Coukos G, Dranoff G. Cancer immunotherapy comes of age. Nature. 2011; 480:480-489.

7. Philips GK, Atkins M. Therapeutic uses of anti-PD-1 and anti-PD-L1 antibodies. Int Immunol. 2015; 27:39-46.

8. Wu L, Wu MO, De la Maza L, Yun Z, Yu J, Zhao Y, Cho J, de Perrot M. Targeting the inhibitory receptor CTLA-4 on $\mathrm{T}$ cells increased abscopal effects in murine mesothelioma model. Oncotarget. 2015; 6:12468-12480.

9. Belcaid Z, Phallen JA, Zeng J, See AP, Mathios D, Gottschalk C, Nicholas S, Kellett M, Ruzevick J, Jackson C,
Albesiano E, Durham NM, Ye X, et al. Focal radiation therapy combined with 4-1BB activation and CTLA-4 blockade yields long-term survival and a protective antigenspecific memory response in a murine glioma model. PLoS One. 2014; 9:e101764.

10. McAllister F, Bailey JM, Alsina J, Nirschl CJ, Sharma R, Fan H, Rattigan Y, Roeser JC, Lankapalli RH, Zhang H, Jaffee EM, Drake CG, Housseau F, et al. Oncogenic Kras activates a hematopoietic-to-epithelial IL-17 signaling axis in preinvasive pancreatic neoplasia. Cancer Cell. 2014; 25:621-637.

11. Brahmer JR, Pardoll DM. Immune checkpoint inhibitors: making immunotherapy a reality for the treatment of lung cancer. Cancer Immunol Res. 2013; 1:85-91.

12. Brown JA, Dorfman DM, Ma FR, Sullivan EL, Munoz O, Wood CR, Greenfield EA, Freeman GJ. Blockade of programmed death-1 ligands on dendritic cells enhances T cell activation and cytokine production. J Immunol. 2003; 170:1257-1266.

13. Taube JM, Klein A, Brahmer JR, Xu H, Pan X, Kim JH, Chen L, Pardoll DM, Topalian SL, Anders RA. Association of PD-1, PD-1 ligands, and other features of the tumor immune microenvironment with response to anti-PD-1 therapy. Clin Cancer Res. 2014; 20:5064-5074.

14. Topalian SL, Sznol M, McDermott DF, Kluger HM, Carvajal RD, Sharfman WH, Brahmer JR, Lawrence DP, Atkins MB, Powderly JD, Leming PD, Lipson EJ, Puzanov I, et al. Survival, durable tumor remission, and long-term safety in patients with advanced melanoma receiving nivolumab. J Clin Oncol. 2014; 32:1020-1030.

15. Li H, Chiappinelli KB, Guzzetta AA, Easwaran H, Yen RW, Vatapalli R, Topper MJ, Luo J, Connolly RM, Azad NS, Stearns V, Pardoll DM, Davidson N, et al. Immune regulation by low doses of the DNA methyltransferase inhibitor 5-azacitidine in common human epithelial cancers. Oncotarget. 2014; 5:587-598.

16. Napolitano M, D'Alterio C, Cardone E, Trotta AM, Pecori B, Rega D, Pace U, Scala D, Scognamiglio G, Tatangelo F, Cacciapuoti C, Pacelli R, Delrio P, et al. Peripheral myeloid-derived suppressor and $\mathrm{T}$ regulatory PD-1 positive cells predict response to neoadjuvant shortcourse radiotherapy in rectal cancer patients. Oncotarget. $2015 ; 6: 8261-8270$.

17. Rhodes DR, Kalyana-Sundaram S, Mahavisno V, Varambally R, Yu J, Briggs BB, Barrette TR, Anstet MJ, Kincead-Beal C, Kulkarni P, Varambally S, Ghosh D, Chinnaiyan AM. Oncomine 3.0: genes, pathways, and networks in a collection of 18,000 cancer gene expression profiles. Neoplasia. 2007; 9:166-180.

18. Bian Y, Hall B, Sun ZJ, Molinolo A, Chen W, Gutkind JS, Waes CV, Kulkarni AB. Loss of TGF-beta signaling and PTEN promotes head and neck squamous cell carcinoma through cellular senescence evasion and cancer-related inflammation. Oncogene. 2012; 31:3322-3332. 
19. Latour S, Tanaka H, Demeure C, Mateo V, Rubio M, Brown EJ, Maliszewski C, Lindberg FP, Oldenborg A, Ullrich A, Delespesse G, Sarfati M. Bidirectional negative regulation of human $\mathrm{T}$ and dendritic cells by $\mathrm{CD} 47$ and its cognate receptor signal-regulator protein-alpha: down-regulation of IL-12 responsiveness and inhibition of dendritic cell activation. J Immunol. 2001; 167:2547-2554.

20. Kim HJ, Cantor H. The path to reactivation of antitumor immunity and checkpoint immunotherapy. Cancer Immunol Res. 2014; 2:926-936.

21. Woods K, Cebon J. Tumor-specific T-cell help is associated with improved survival in melanoma. Clin Cancer Res. 2013; 19:4021-4023.

22. Villaruz LC, Kalyan A, Zarour H, Socinski MA. Immunotherapy in lung cancer. Transl Lung Cancer Res. 2014; 3:2-14.

23. Fakhry C, Gillison ML. Clinical implications of human papillomavirus in head and neck cancers. J Clin Oncol. 2006; 24:2606-2611.

24. Lassen P. The role of Human papillomavirus in head and neck cancer and the impact on radiotherapy outcome. Radiother Oncol. 2010; 95:371-380.

25. Sepiashvili L, Bruce JP, Huang SH, O’Sullivan B, Liu FF, Kislinger T. Novel insights into head and neck cancer using next-generation "omic" technologies. Cancer Res. 2015; 75:480-486.

26. Ang KK, Harris J, Wheeler R, Weber R, Rosenthal DI, Nguyen-Tan PF, Westra WH, Chung CH, Jordan RC, Lu C, Kim H, Axelrod R, Silverman CC, et al. Human papillomavirus and survival of patients with oropharyngeal cancer. N Engl J Med. 2010; 363:24-35.

27. Lyford-Pike S, Peng S, Young GD, Taube JM, Westra WH, Akpeng B, Bruno TC, Richmon JD, Wang H, Bishop JA, Chen L, Drake CG, Topalian SL, et al. Evidence for a role of the PD-1:PD-L1 pathway in immune resistance of HPVassociated head and neck squamous cell carcinoma. Cancer Res. 2013; 73:1733-1741.

28. Malm IJ, Bruno TC, Fu J, Zeng Q, Taube JM, Westra W, Pardoll D, Drake CG, Kim YJ. Expression profile and in vitro blockade of programmed death-1 in human papillomavirus-negative head and neck squamous cell carcinoma. Head Neck. 2015; 37:1088-1095.

29. Crane CA, Panner A, Murray JC, Wilson SP, Xu H, Chen L, Simko JP, Waldman FM, Pieper RO, Parsa AT. PI(3) kinase is associated with a mechanism of immunoresistance in breast and prostate cancer. Oncogene. 2009; 28:306-312.

30. Levovitz C, Chen D, Ivansson E, Gyllensten U, Finnigan JP, Alshawish S, Zhang W, Schadt EE, Posner MR, Genden EM, Boffetta P, Sikora AG. TGFbeta receptor 1: an immune susceptibility gene in HPV-associated cancer. Cancer Res. 2014; 74:6833-6844.

31. Bian Y, Terse A, Du J, Hall B, Molinolo A, Zhang P, Chen W, Flanders KC, Gutkind JS, Wakefield LM, Kulkarni AB. Progressive tumor formation in mice with conditional deletion of TGF-beta signaling in head and neck epithelia is associated with activation of the PI3K/Akt pathway. Cancer Res. 2009; 69:5918-5926.

32. Highfill SL, Cui Y, Giles AJ, Smith JP, Zhang H, Morse E, Kaplan RN, Mackall CL. Disruption of CXCR2-mediated MDSC tumor trafficking enhances anti-PD1 efficacy. Sci Transl Med. 2014; 6.237-267

33. Lee BR, Chang SY, Hong EH, Kwon BE, Kim HM, Kim YJ, Lee J, Cho HJ, Cheon JH, Ko HJ. Elevated endoplasmic reticulum stress reinforced immunosuppression in the tumor microenvironment via myeloid-derived suppressor cells. Oncotarget. 2014; 5:12331-12345.

34. Yao A, Liu F, Chen K, Tang L, Liu L, Zhang K, Yu C, Bian G, Guo H, Zheng J, Cheng P, Ju G, Wang J. Programmed death 1 deficiency induces the polarization of macrophages/microglia to the M1 phenotype after spinal cord injury in mice. Neurotherapeutics. 2014; 11:636-650.

35. Majeti R, Chao MP, Alizadeh AA, Pang WW, Jaiswal S, Gibbs KD Jr., van Rooijen N, Weissman IL. CD47 is an adverse prognostic factor and therapeutic antibody target on human acute myeloid leukemia stem cells. Cell. 2009; 138:286-299.

36. Fujii S, Liu K, Smith C, Bonito AJ, Steinman RM. The linkage of innate to adaptive immunity via maturing dendritic cells in vivo requires CD40 ligation in addition to antigen presentation and CD80/86 costimulation. J Exp Med. 2004; 199:1607-1618.

37. Matozaki T, Murata Y, Okazawa H, Ohnishi H. Functions and molecular mechanisms of the CD47-SIRPalpha signalling pathway. Trends Cell Biol. 2009; 19:72-80.

38. Kuznetsov HS, Marsh T, Markens BA, Castano Z, Greene-Colozzi A, Hay SA, Brown VE, Richardson AL, Signoretti S, Battinelli EM, McAllister SS. Identification of luminal breast cancers that establish a tumor-supportive macroenvironment defined by proangiogenic platelets and bone marrow-derived cells. Cancer Discov. 2012; 2:1150-1165.

39. Staron MM, Gray SM, Marshall HD, Parish IA, Chen JH, Perry CJ, Cui G, Li MO, Kaech SM. The transcription factor FoxO1 sustains expression of the inhibitory receptor PD-1 and survival of antiviral CD8(+) T cells during chronic infection. Immunity. 2014; 41:802-814.

40. Soto-Pantoja DR, Terabe M, Ghosh A, Ridnour LA, DeGraff WG, Wink DA, Berzofsky JA, Roberts DD. CD47 in the tumor microenvironment limits cooperation between antitumor T-cell immunity and radiotherapy. Cancer Res. 2014; 74:6771-6783.

41. Tseng SY, Dustin ML. T-cell activation: a multidimensional signaling network. Curr Opin Cell Biol. 2002; 14:575-580.

42. Gabrilovich DI, Nagaraj S. Myeloid-derived suppressor cells as regulators of the immune system. Nat Rev Immunol. 2009; 9:162-174.

43. Weed DT, Vella JL, Reis IM, De la Fuente AC, Gomez C, Sargi Z, Nazarian R, Califano J, Borrello I, Serafini P. 
Tadalafil reduces myeloid-derived suppressor cells and regulatory $\mathrm{T}$ cells and promotes tumor immunity in patients with head and neck squamous cell carcinoma. Clin Cancer Res. 2015; 21:39-48.

44. Zandberg DP, Strome SE. The role of the PD-L1:PD-1 pathway in squamous cell carcinoma of the head and neck. Oral Oncol. 2014; 50:627-632.

45. Weber JS, D’Angelo SP, Minor D, Hodi FS, Gutzmer R, Neyns B, Hoeller C, Khushalani NI, Miller WH Jr., Lao CD, Linette GP, Thomas L, Lorigan P, et al. Nivolumab versus chemotherapy in patients with advanced melanoma who progressed after anti-CTLA-4 treatment (CheckMate 037): a randomised, controlled, open-label, phase 3 trial. Lancet Oncol. 2015; 16:375-384.

46. Naidoo J, Page DB, Li BT, Connell LC, Schindler K, Lacouture ME, Postow MA, Wolchok JD. Toxicities of the Anti-PD-1 and Anti-PD-L1 Immune Checkpoint Antibodies. Ann Oncol. 2015; 10.1093/annonc/mdv383.

47. Baccelli I, Stenzinger A, Vogel V, Pfitzner BM, Klein C, Wallwiener M, Scharpff M, Saini M, Holland-Letz T, Sinn HP, Schneeweiss A, Denkert C, Weichert W, et al. Co-expression of MET and CD47 is a novel prognosticator for survival of luminal breast cancer patients. Oncotarget. 2014; 5:8147-8160.

48. Parikh F, Duluc D, Imai N, Clark A, Misiukiewicz K, Bonomi M, Gupta V, Patsias A, Parides M, Demicco EG, Zhang DY, Kim-Schulze S, Kao J, et al. Chemoradiotherapy-induced upregulation of PD-1 antagonizes immunity to HPV-related oropharyngeal cancer. Cancer Res. 2014; 74:7205-7216.
49. Sun ZJ, Zhang L, Hall B, Bian Y, Gutkind JS, Kulkarni AB. Chemopreventive and chemotherapeutic actions of mTOR inhibitor in genetically defined head and neck squamous cell carcinoma mouse model. Clin Cancer Res. 2012; 18:5304-5313.

50. Zhang L, Sun ZJ, Bian Y, Kulkarni AB. MicroRNA-135b acts as a tumor promoter by targeting the hypoxia-inducible factor pathway in genetically defined mouse model of head and neck squamous cell carcinoma. Cancer Letters. 2013; 331:230-238.

51. Trellakis S, Bruderek K, Hutte J, Elian M, Hoffmann TK, Lang S, Brandau S. Granulocytic myeloid-derived suppressor cells are cryosensitive and their frequency does not correlate with serum concentrations of colony-stimulating factors in head and neck cancer. Innate Immun. 2013; 19:328-336.

52. Yu GT, Bu LL, Zhao YY, Liu B, Zhang WF, Zhao YF, Zhang L, Sun ZJ. Inhibition of mTOR reduce Stat3 and PAI related angiogenesis in salivary gland adenoid cystic carcinoma. Am J Cancer Res. 2014; 4:764-775.

53. Huang CF, Zhang L, Ma SR, Zhao ZL, Wang WM, He KF, Zhao YF, Zhang WF, Liu B, Sun ZJ. Clinical significance of Keap1 and Nrf2 in oral squamous cell carcinoma. PLoS One. 2013; 8:e83479.

54. Eisen MB, Spellman PT, Brown PO, Botstein D. Cluster analysis and display of genome-wide expression patterns. Proc Natl Acad Sci U S A. 1998; 95:14863-14868. 